\title{
THE EFFECT OF IMPRESSION MANAGEMENT STRATEGIES ON EARNINGS RELEASE ANNOUNCEMENTS
}

\author{
D. Elaine Sanders, Ph.D. \\ Jane L. Coelho, C.P.A., M.B.A. \\ University of Texas at San Antonio \\ San Antonio, TX
}

\begin{abstract}
This study examines the effect of impression management on the reactions of individual decision-makers in the presence of positive or negative information. In a stock price prediction task void of impression management, inexperienced investors had a more pessimistic expectation for the future stock price when unfavorable financial results were presented than when favorable financial results were presented or when investment experience was present. Predictions were also consistent with the theory of diminishing marginal sensitivity. Impression management in the form of management commentary significantly shifted stock price expectations in the loss domain but did not affect reactions in the domain of gains. The results were consistent across prior investment experience for both the reaction to diminishing marginal sensitivity and impression management.
\end{abstract}

\section{Introduction}

Investors have numerous sources of financial and financially related information available for use in their fundamental decisions. The first purpose of this research is to explore the similarities and differences between how individuals make investment-related decisions and the outcomes predicted by the prospect theory value function (Kahneman \& Tversky, 1979; Kahneman \& Tversky, 1984). This hypothetical value function is normative in nature; that is, it defines how individuals actually do make decisions rather than how they should make decisions. Three basic tenets may be used to describe this value function. First, individuals are assumed to select outcomes based on their relation to some reference point (usually the status quo). Second, an individual's reaction will be greater in the domain of losses than in the domain of gains. Third, individuals experience diminishing marginal sensitivity within the domain of gains or losses (Hogarth, 1989).

Management has some control over the frame through which an investor views financial information. Through the use of voluntary disclosures, management influences the reactions of investors to financial information (e.g. earnings disclosures). This desire to present management's position in the most advantageous way and to 
subsequently influence investor behavior is commonly called impression management (Giacalone, 1989; Murray, Rao \& Schmidt, 1995). The second purpose of this research is to explore the similarities and differences between how individuals make investment-related decisions and the outcomes predicted by the value function in the presence of additional disclosure by management.

In the current study, an experiment was conducted to discern how the reactions of decision-makers to accounting data fit into the hypothetical value function and to observe the impact of impression management on those reactions. Specifically, the relation between earnings reports and individual investor's opinions about potential changes in stock price is observed. This research extends extant research in the area of prospect theory by showing a practical application of the theory in a business environment. The research also extends cxisting accounting research by suggesting that elements of prospect theory may enrich the understanding of accounting reporting issues (i.e., individuals don't react in a rational manner to reported gains/losses or increases/decreases to net income) and by showing how impression management may be used by management to control for reactions to financial information.

The balane of the paper is organized as follows. The next section contains a discussion of the literature pertaining to the value curve and impression management. The third section contains the development of the hypotheses. The fourth and fifth sections provide a detailed description of the methodology used and the analysis of the experimental results. The final section contains a discussion of the results, the limitations of the study, and suggestions for future research.

\section{Theoretical Background}

For the fiscal years 1991, 1992, and 1993, American Express Company (Annual Report, 1992 and 1993) reported net incomes (in millions) of $\$ 789$, $\$ 461$, and $\$ 1,478$. That is a loss in 1992 (relative to 1991 net income) of $\$ 328$ and a gain (relative to 1992 net income) of $\$ 1,017$. Earnings per share (e.p.s.) for those same years were $\$ 1.59, \$ .88$ (a loss of $\$ .71$ relative to 1991 e.p.s.), and $\$ 2.92$ (a gain of $\$ 2.04$ relative to 1992 e.p.s.). What if you were an investor in Amercian Express? How would you have felt about your investment in 1992? In 1993? The way decision-makers react to these gains and losses can, theoretically, be described using the value function in Figure 1. This value function was derived in partial explanation of the way individuals make risky choice decisions, and that explanation is referred to as prospect theory.

\section{Prospect Theory}

Prospect theory is a descriptive economic theory developed by Daniel Kahneman and Amos Tversky as an extension to expected utility theory (Kahneman \& Tversky, 1979). These pioneers in behavioral economics observed that in situations marked by uncertainty, the underlying assumptions of both expected value and expected 


\section{Figure 1}

\section{The Hypothetical Value Function}

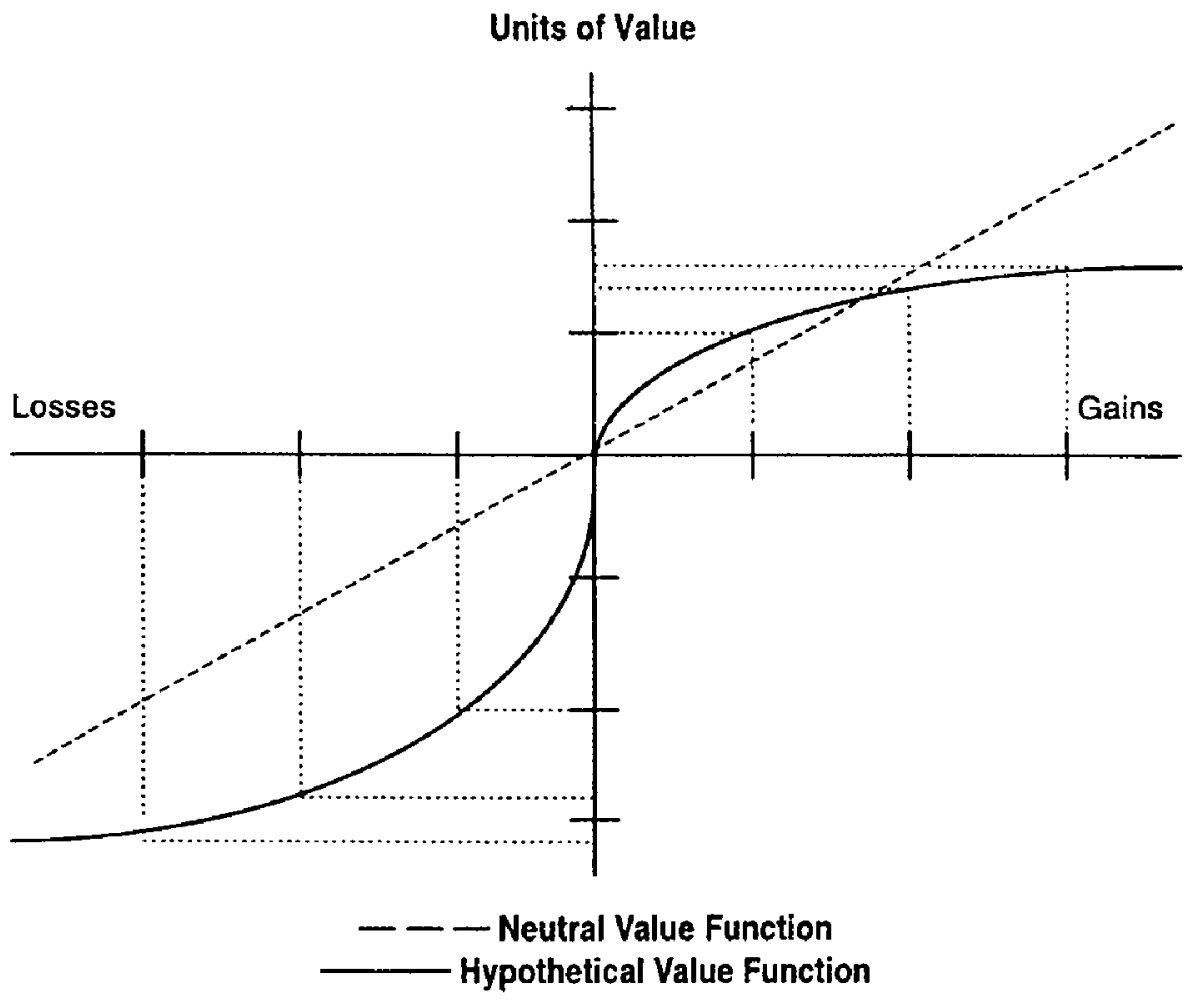

utility theory were systematically violated. Their observations led to the development of prospect theory, which attempts to explain the deviations from rational decision-making in conditions of uncertainty.

The hypothetical value function presented in Figure 1 depicts the tenets outlined in the prospect theory literature. The origin represents the neutral reference point or status quo. In our example, this would be last year's net income or last year's e.p.s. Outcomes in the positive domain (upper-right quadrant) are deemed to be gains relative to the origin. Outcomes in the negative domain (lower-left quadrant) are evaluated as losses.

Note that the slope of the hypothetical value function is steeper in the domain of losses than in the domain of gains as it moves away from the origin. This contrast depicts the second basic premise of this value function commonly known as loss aversion (Kahneman \& Tversky, 1984). The concept of loss aversion relates to the intensity or severity of the reaction when comparing gain scenarios to loss scenarios. When individuals perceive themselves in the negative domain (a loss situation) their negative reaction is more severe than is their positive reaction to an equivalent gain (Bazerman, 1990; Mayer, 1995). As Fuller (1996) succinctly stated, "The pain associated with a given amount of loss 
is greater than the pleasure derived by an equivalent gain." Empirical evidence suggests that the reactions in the negative domain can be twice as great as reactions in the positive domain (Kahneman, Knetsch \& Thaler, 1990; Tversky \& Kahneman, 1991). In our example, American Express investors saw a loss of $\$ .71$ per share in fiscal 1992 . According to the value function, investors would feel up to twice as unsatisfied with the $\$ .71$ loss in e.p.s. as they would have felt satisfied with a $\$ .71$ gain in e.p.s. for that same year.

The hypothetical value function is concave in the domain of gains and convex in the domain of losses with the curve becoming relatively flat as it moves away from the origin. The shape of the curve suggests diminishing marginal sensitivity in both the positive and negative domains. Stated simply, a gain/loss of $\$ 2$ does not give twice the pleasure/pain of a gain/loss of $\$ 1$. In fiscal 1993, our American Express investors saw a \$2.04 gain in e.p.s. relative to 1992. How different do you think their satisfaction level would have been if the gain had been $\$ 1.90$ greater than 1992 e.p.s? $\$ 2.00$ ? $\$ 2.10$ ? $\$ 2.50$ ? $\$ 3.00$ ?

An important aspect of prospect theory that relates to this study is the effect of framing on decision making. In the American Express example, what frame has been encouraged? The scenario has been framed as a change in e.p.s. problem. Are e.p.s. changes the only factor that drives an investor's assessment of corporate performance? Most probably not. Framing, however, allows the discussion to be focused on preferred issues and away from other issues. Framing relates to both the methods used to present information and the individual interpretation of that information (Bazerman, 1990). In conditions of uncertainty, a decision frame is formed by an individual based on the information provided and reflects his or her personal interpretation of circumstances. In forming a decision frame, the individual defines what is important or significant in selecting among alternatives.

As decisions are framed, individuals may compromise their potential to make optimal choices. A frame will eliminate information, which is deemed irrelevant or unimportant, relating to the problem. Therefore, once a decision is framed, the individual may have a compromised perspective on the problem. This is a direct violation of the invariance axiom of expected utility theory (von Neumann \& Morgenstern, 1947; Luce \& Raiffa, 1957). The invariance axiom of expected utility theory requires that qualitative descriptions of alternatives will not affect decision making (e.g., the happiness generated by finding $\$ 10$ on a sidewalk will be exactly equal to the unhappiness generated by finding that $\$ 10$ you are carrying has blown away). By definition, framing results in an individual taking a certain posture or stance regarding a decision. This suggests that the framing of a problem will directly affect how an individual will respond to the situation.

The framing of a decision problem will directly influence the perspective of the decision-maker and, therefore, the reaction that can be expected. While the positive or negative frame of the decision does not affect diminishing marginal 
sensitivity, both reactions are affected. If a situation is framed positively, the decision will be viewed as a gain situation, and the decision-maker should exhibit a limited positive reaction to the information. If a situation is framed negatively, the decision will be viewed as a loss situation, and the decisionmaker should behave in a more pronounced negative manner. The decisionmaker in this frame should exhibit a greater reaction to the negative information than if the decision were positively framed (Brockner, 1992).

\section{Impression Management}

Impression management is defined as the tendency to present oneself in a socially desirable way (Giacalone, 1989) or the process by which other people's reactions are manipulated (Murray et al., 1995). Impression management, sometimes called "strategic communication" (Allen \& Caillovet, 1994), refers to the strategies used by organizations to create, maintain, or improve their public image. Bromley (1993) describes the entire public relations function as the corporate equivalent of impression management.

Impression management can be used in a number of ways by management. The different strategies employed are a function of the various target audiences. Employees, customers, competitors, shareholders and potential investors have vastly different perspectives in evaluating the performance of the organization. Management recognizes these different needs and attempts to utilize the appropriate communication strategy.

A vast amount of financial information is provided to the market as a result of regulatory requirements. Financial statements, footnotes, and audit reports have very specific guidelines for presentation and disclosure. This information is limited in its potential for furthering the public image or perception of the corporation. Voluntary disclosures, however, present a unique opportunity for the application of an impression management strategy.

The market for corporate control motivates the voluntary disclosure of information (Kaplan, Pourciau \& Reckers, 1990). In the absence of voluntary disclosures specifically designed to control perception, stockholders or outsiders may perceive management to be incompetent or incapable. The ultimate end result could be a change in management. With the goal of maintaining shareholder support, management will utilize various impression management strategies. These efforts extend well beyond the skillfully written news release. To improve their image in the business community, most major corporations have established investor relations programs. Corporations also make efforts to promote their social responsibility by supporting non-profit organizations. These programs are all part of a public relations campaign highlighting the skill, competence, and responsiveness of management.

Impression management strategies are characterized by their self-serving posture. A strategy that is self-serving is typified by one taking credit for positive outcomes and placing blame on others for negative outcomes. Giacalone 
(1989) presents two types of impression management strategies based on the two elemental situations management will attempt to control - "good news" and "bad news". Demotion-preventative strategies are used in the negative or "bad news" domain, while promotion-enhancing strategies are used in the positive or "good news" domain.

Demotion-preventative strategies are used when blame avoidance is the desirable course of action. Kaplan et al. (1990) discuss three categories of impression management strategies found in situations with negative outcomes: the "excuse" strategy, the "justification" strategy, and the "change" strategy.

When management utilizes an "excuse" strategy, the explanation for the unfavorable outcome is directed externally. For example, unfavorable earnings could be attributed to a weak economy or an industry slump. An excuse strategy is a means of distancing management from the unfavorable event. A study conducted by Wood and Mitchell (1981) found that the intensity of the unfavorable reaction was decreased when an excuse was offered in the annual report. However, it should also be noted that the results of the Kaplan et al. (1990) study indicate this strategy to be the least effective of the three strategies examined.

A "justification" strategy is characterized by accepting responsibility for the unfavorable outcome. The action will then be justified by demonstrating how the benefits of the action exceed its cost. For example, management may emphasize new cost-effective measures placed into the system. In the short run, the cost of implementation may be high, but in the long run profits will increase.

A third impression management strategy is referred to as the "change" strategy (Chugh \& Meador, 1984). The change strategy avoids excuses or justification for the unfavorable outcome and merely focuses on the future. It employs a proactive approach to problem solving instead of a reactive approach. Managers using this strategy would simply discuss the plans and strategies for the future and ignore the current unfavorable results.

Let's return briefly to our American Express example. In 1992, with a decrease in net income of $\$ 328$ and a decrease in e.p.s. of $\$ .71$, the Letter to Shareholders in the American Express annual report began as follows:

From a shareholder's perspective, 1992 was not a good year for American Express. We met few of your - or our - expectations, particularly in terms of bottom-line financial results. Our net income and return on equity were inadequate, and we had too many surprises of a financial and management nature. I'm disappointed in our performance, and I know you must be.

It is my objective to see that we do much better in the future. I believe we can.

Although we didn't meet shareholders' expectations in terms of financial performance, we did accomplish a number of significant things that augur well for the future. Travel 
Related Services put in place the major elements of its strategy to fix its problems.... (Annual Report, 1992).

The letter was short, only six pages, to the point and contained a single photograph of President and C.E.O. Harvey Golub. Where does this letter fit among the strategies just discussed?

When financial results are favorable, Giacalone (1989) states that promotionenhancing strategies are typically used. While these strategies are used less often than demotion-preventative techniques, managers still use them to enhance and strengthen their image to the shareholders. Management wishes to emphasize their own role in producing favorable results (Kaplan et al., 1990). Impression management devices in favorable situations may include descriptions of new programs implemented, visual presentations (e.g. photographs, graphs, or charts), or plans for future successes. These strategies are less influential on investors than the strategies used to soften the severity of the investors' reactions to poor company performance (Giacalone, 1989).

The Letter to Shareholders in the 1993 American Express annual report was nineteen pages in length, had three executive photographs, five promotional photographs, five graphs, and two tables. In this year, net income increased by $\$ 1,017$ and e.p.s. increased by $\$ 2.04$. The Letter began as follows:

1993 was an extraordinary time for American Express. We started the year in controversy and on the defensive. We finished the year with a long list of accomplishments - including achieving some of the best financial results in our history, creating a new foundation for growth with highly-motivated, reenergized employees, and rebuilding relationships with important customer groups.

As with all corporations, our overriding business objective is to create shareholder value. We believe the best way to accomplish this is to work toward making American Express the world's most respected service brand - not out of a sense of arrogance or ambition - but because brands have value and great brands like ours can have great value... (Annual Report 1993).

Accounting narratives are the main vehicles for impression management used by organizations to control reaction to earnings announcements. Accounting narratives include the president's letter and the management discussion and analysis found in annual reports, voluntary press releases, and all other forms of voluntary disclosures.

Using an impression management strategy, management can qualify every financial item reported on and use any of the above-mentioned techniques to attempt to control and influence investors' reactions. The accounting narrative, 
being the most easily read and understood part of the annual report, offers management an opportunity to address the events that occurred during the year and that affected financial results (Jones, 1996).

In summary, managers have the motive, opportunity and ability to use impression management to influence shareholder reactions to earnings announcements. Managers are motivated by their desire to maintain shareholder support. The opportunity to influence this perception is provided by the use of accounting narratives that are closely associated with mandatory earnings disclosures. Through accounting narratives, managers get the freedom of unregulated commentary while enjoying the close association with regulated financial results. Given this opportunity, managers will present current earnings in a manner that maximizes the potential for continued support from the shareholders.

\section{Hypotheses}

Accounting is commonly described as the language of business. Nowhere is this truism more aptly portrayed than in the media, where earnings and earningsrelated information serve as signals of the past and future profitability of a company. The financial information provided in earnings releases is the final product of accounting effort and has been empirically shown to affect shareholder behavior (for examples, see Ball \& Brown, 1968; Lev \& Ohlson, 1982; Kormendi \& Lipe, 1987).

Managers have a vested interest in the way earnings are perceived by shareholders because earnings are an important signal of managerial ability. Management teams wish to appear strong and in control of the future of the company, thus assuaging any inclination on the part of the shareholders or outside interests to make management changes. As a result, management will use voluntary disclosures to control (or attempt to control) the degree of reaction to earnings releases (King, Pownall \& Waymire, 1990).

If the value function can be transferred into investment decisions, in a controlled environment, investors will react more negatively to earnings presented in the negative (loss) domain than to earnings presented in the positive (gain) domain. That is, in an environment of only gain or loss information, reactions will be greater for losses than for gains. While the assumption that earnings will be presented without some discussion is unrealistic, especially in the domain of losses, the controlled experimental environment allows for the testing of the hypothetical value function (Kahneman \& Tversky, 1979; Kahneman \& Tversky, 1984). The first hypothesis, stated in the alternative, is

Hypothesis 1: Investors' reactions to losses will be greater than reactions to corresponding gains. 
The value function also displays marginal diminishing sensitivity in both the positive and negative domains. From the perspective of an investor, a $5 \%$ or $10 \%$ increase in earnings (using last year's earnings as a reference point) would be equally as satisfying, while a $5 \%$ or $10 \%$ decrease in earnings would be equally as painful. In this case, prospect theory would support the null hypothesis of failure to support a change in reaction across levels of gain or loss.

Hypothesis 2: Investors" reactions will be unaffected by the level of loss or gain.

A growing body of literature supports the contention that the president's letter and management analysis and commentary in annual reports has a self-serving nature (Kaplan et al., 1990). Even so, the studies also show that investors are swayed by these reporting strategies (Staw, McKechnie \& Puffer, 1983).

The current study uses disclosures provided through financial publications (e.g. Wall Street Journal). Earnings reports typically contain both accounting numbers and commentary. The impression management literature suggests that the reaction to losses should be altered in the presence of commentary. That is, managers will actively work to frame a loss scenario in such a manner to minimize the reaction potential of investors. The disclosures provided will serve as an intervening variable in that the earnings release will be qualified before comparison to last year's earnings (the reference point).

The literature suggests, however, that impression management is not used as frequently and is less effective in the domain of gains (Giacalone, 1989) in these financial publications. In the presence of impression management, investors will be cautious and less willing to revise their opinions in the domain of gains.

The third and fourth hypotheses of this study involve the effect of impression management in the domain of gains and losses. Impression management will help reduce the impact of bad news but will not affect the impact of good news.

Hypothesis 3: Impression management will reduce the impact of negative information.

Hypothesis 4: Impression management will not affect the impact of positive information.

\section{Methodology}

\section{Design}

A between-subjects experiment was conducted to test the hypotheses. In a controlled laboratory experiment, all possible variables not pertinent to the immediate question being tested are kept at a minimum. This is done by reducing a real-world situation to its basic elements and then rigorously controlling the 
information subjects may use to make a decision. While the information provided may not be realistic from a real-world perspective, the information is carefully tailored to elicit and measure a reaction by a decision maker.

The experiment contained a $2 \times 2 \times 4$ design with two levels of domain (positive or negative), two levels of impression management (absent or present), and four degrees of change within domain $(20 \%, 40 \%, 60 \%$, or $80 \%)$. In addition, one cell was added to the design as a control. Information from one of the seventeen total cells was distributed randomly to each subject.

\section{Task}

In order to test the three hypotheses, the researchers developed a series of fictitious news releases. The releases were based on an actual article published in the Wall Street Journal detailing the financial results of a major soft drink company. To maintain control over the scenarios, portions of the article were manipulated to obtain one release for each of the seventeen conditions discussed above. Each release described the earnings results for FizzyCo Inc., a fictitious fast food and beverage conglomerate.

Eight news releases described favorable (positive) earnings results for the year. Four of these releases provided only accounting data - gross income, per share financial information and the percentage increase over the previous fiscal year. The other four scenarios provided commentary to support and describe the favorable results in addition to the numeric financial data. Within each impression management condition (absent/present), the news releases described gains over the previous period in $20 \%$ increments up to $80 \%$. Examples of the with and without impression management scenarios in the gain domain are presented below:

\section{Without Impression Management}

FizzyCo Inc. reported today that net income increased (20\%, $40 \%, 60 \%, 80 \%$ ) for the fiscal year ended December 31, 1996. The food and beverages giant reported net income of $(\$ 224$, $\$ 262, \$ 299, \$ 336)$ million, or $(13,15,18,20)$ cents a share. Last year, FizzyCo earned $\$ 187$ million, or eleven cents a share.

\section{With Impression Management}

FizzyCo Inc., capping its best year in recent memory, said net income increased $(20 \%, 40 \%, 60 \%, 80 \%)$ for the fiscal year ended December 31,1996, reflecting phenomenal results in the company's restaurant and international beverage operations. 
The food and beverages giant reported net income of $(\$ 224$, $\$ 262, \$ 299, \$ 336)$ million, or $(13,15,18,20)$ cents a share, including $\$ 323$ million in charges. The one-time items were tied primarily to a restructuring of overseas beverage operations and the company's casual-dining business. As expected, FizzyCo said yesterday that it plans to purchase several small dining chains.

Last year, FizzyCo earned $\$ 187$ million, or eleven cents a share, which included a one-time accounting charge of $\$ 384$ million.

FizzyCo noted that two core divisions - Continental Beverages and Dippin' Chips - continued to perform well, posting profits up $16 \%$ each for the year.

Conversely, eight news releases described unfavorable (negative) earnings results for the year. The wording was consistent for both favorable and unfavorable earnings. Four releases provided no details regarding the losses (i.e. no impression management) while the remaining four provided commentary regarding the source of the losses. The eight news releases described losses up to $80 \%$ over the previous year in increments of $20 \%$. Examples of the with and without impression management scenarios in the loss domain are presented below:

Without Impression Management:

FizzyCo Inc. reported today that net income decreased $(20 \%$, $40 \%, 60 \%, 80 \%$ ) for the fiscal year ended December $31,1996$. The food and beverages giant reported net income of $(\$ 150$, $\$ 112, \$ 75, \$ 37)$ million, or $(9,7,4,2)$ cents a share. Last year, FizzyCo earned $\$ 187$ million, or eleven cents a share.

\section{With Impression Management:}

FizzyCo Inc., capping its toughest year in recent memory, said net income decreased $(20 \%, 40 \%, 60 \%, 80 \%)$ for the fiscal year ended December 31, 1996, reflecting charges and poor results in the company's restaurant and international beverage operations. The food and beverages giant reported net income of $(\$ 150, \$ 112$, $\$ 75, \$ 37)$ million, or $(9,7,4,2)$ cents a share, including $\$ 323$ million in charges. The one-time items were tied primarily to a restructuring of overseas beverage operations and the company's casual-dining business. As expected, FizzyCo said yesterday that it plans to sell several small dining chains. 
Last year, FizzyCo earned $\$ 187$ million, or eleven cents a share, which included a one-time accounting charge of $\$ 384$ million.

FizzyCo noted that two core divisions - Continental Beverages and Dippin' Chips - continued to perform well, posting profits up $16 \%$ each for the year.

For the sake of consistency across all cells providing commentary, a single impression management strategy was selected. Because both favorable and unfavorable results were being presented (depending on domain), a "justification" strategy was selected. Kaplan et al. (1990) find this strategy to be effective for "enhancing judgments and decision about the firm" (page 77). This strategy allows for the provision of a loss explanation and discussion of overall results and future benefits in both domains.

The control condition described the earnings results as stable or flat when compared to the previous year. Only accounting numbers were presented in the control condition (i.e., no commentary was provided).

The instructions asked subjects to assume they were investors in the conglomerate and to read the article regarding the company's most recent earnings results. They were then asked to predict the direction of the company's stock price based on the disclosure presented by marking a scale provided in the task. The task concluded with a written protocol of the decision process.

\section{Subjects}

The experimental task was completed by 257 subjects. The subjects participating in the study were student volunteers currently enrolled in upper-level accounting courses at a southwestern university. Accounting students were deemed appropriate participants for this experiment. The subjects had reasonable familiarity with the basic terminology contained in standard earnings releases. The researchers felt the subjects possessed the appropriate academic and analytical skills to reach a reasonable conclusion regarding the direction of the stock price. Because the student subjects were not expected to proxy for actual experienced investors, the researchers did not feel that for purposes of this experiment an advanced level of investment knowledge was required.

\section{Procedure}

The experiment was conducted during regularly scheduled class time. The subjects were under the direct observation of the researchers at all times. After a brief introduction, each subject was asked to complete and sign a Statement of Informed Consent. The subjects were asked not to consult their textbooks, notes or each other while completing the instrument. Once the consent forms were completed and collected, the researchers distributed the different versions of the task on a random basis. The instrument consisted of the task and the exit 
questionnaire. There was no time constraint for completing the experiment. Completion times varied due to the varying lengths of the news releases.

\section{Analysis and Results}

Nine subjects were dropped from the analysis due to incomplete instruments. A total of 248 usable instruments were available for analysis in the seventeen cells. The exit questionnaire provided some insightful background information on the subjects. Ninety-one percent of the sample consisted of Juniors and Seniors in the college of business. Accounting students currently enrolled in graduate-level courses made up the remaining nine percent of the sample. The sample was almost evenly divided between males and females at $47 \%$ and $53 \%$ respectively. Forty-two percent of the subjects had either current or prior experience with investments in stock. A macro analysis of these exit questionnaire variables (class level, gender, and investment experience) suggested no effect for the control variables.

\section{Control Condition}

Fifteen subjects were assigned to the control condition. In this condition, subjects were given no commentary and were told that the financial performance of the firm was consistent with the prior year's performance. On a Likert scale of $+/-5$, with 0 indicating no change in stock price, the average response of the subjects was -.81 . This average response is statistically different (at $\alpha=.05$, Scheffe) from the average responses in three of the four general conditionspositive domain with and without impression management $(\mu=1.03$ and $\mathrm{m}=$ 1.65) and negative domain without impression management $(\mu=-1.55)$. The average response in the control group was not statistically different from the average response in the negative domain with impression management $(\mu=$ 0.11 ). This analysis suggests that the overall direction of the responses was consistent with expectations.

\section{Tests of the Hypotheses}

The basic proposition of the value curve is posited in hypothesis 1 . That is, the reaction to negative information will be greater than the reaction to positive information. To test hypothesis one, only the cells containing no impression management were examined. Figure 2 presents the means for each degree of change for the positive and negative domains. To measure the difference in means, the four degrees of change in each domain were collapsed to measure the overall (average) degree of change between the positive and negative domains. In other words, was the overall average in the negative domain further from zero (in a negative direction) than the distance from zero to the overall average in the positive domain (in a positive direction)? 
Figure 2

Reaction to Gains and Losses

(Hypothesis 1)

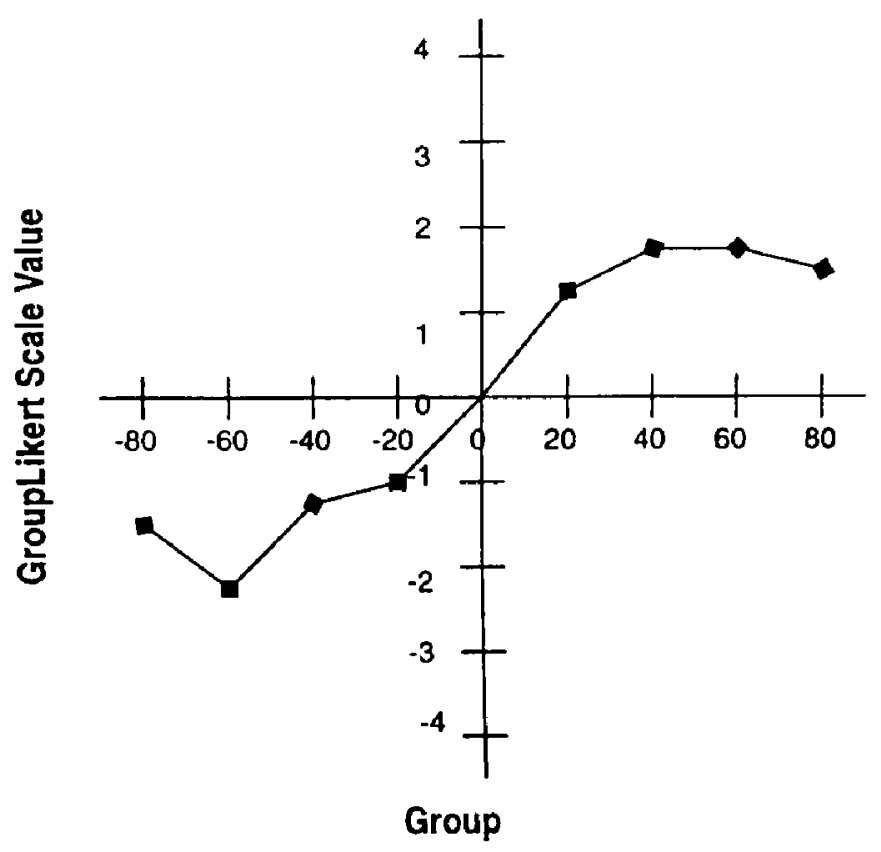

The absolute values of the means for the positive and negative domain were used to measure the difference in reaction to the positive and negative information reported. The difference in the absolute value of the means between the two domains was not statistically significant $(F=1.72, p=0.4892)$ and fails to support the first hypothesis. The subjects, on average, did not have a more severe reaction to losses than to gains.

Prior research suggests that sophisticated and unsophisticated (experienced and inexperienced) investors may utilize information differently in assessing stock value (Hand, 1990; Burns, 1995; Murray et al., 1995; De Bondt \& Thaler, 1985; De Bondt \& Thaler, 1987). Because of the possible mixed demographics of the subject pool (the university has large numbers of second career and full-time employed students), prior investment experience was controlled for through a series of questions in the exit questionnaire. Information from the exit questionnaire suggested that $27 \%$ of the subjects in the positive domain had prior investment experience, and $58 \%$ who were in the negative domain had investment experience.

The test of hypothesis one required subjects to make stock price change predictions based on a very limited set of information. Subjects without investment experience may have used only the information provided in their decision process. Subjects with investment experience, on the other hand, may have 
realized that potential causes of the change could possibly exist. As one subject stated in the written protocol of the task, "There could be reasons that are valid for the decline in income that the publication did not include."

An ANOVA was used to test whether subjects with investment experience arrived at different predictions than subjects without investment experience. A statistically significant interaction (at $\alpha=.10$ ) was found between investment experience and domain $(\mathrm{F}=4.38, \mathrm{p}=.0583)$.

The data were separated into investment experience groups and were reanalyzed to further test the first hypothesis. Figure 3 presents a visual representation of the data separated by investment experience. The question of interest was again whether investor reactions would be greater in the negative domain than in the positive domain. The absolute values of the mean stock price predictions were again compared. Statistically significant differences $\left(\mu_{\mathrm{pms}}=1.56, \mu_{\mathrm{nc}}=.914\right)$ were not found within the group with investment experience. In the no investment experience group, however, the absolute mean differences of the two domains $\left(\mu_{\mathrm{pus}}=1.69, \mu_{\mathrm{ncg}}\right.$ $=-2.43)$ were statistically different $(F=6.42, p=.0445)$. The subjects without investment experience reacted more strongly to a loss than to a gain, while the subjects with investment experience treated losses and gains cqually.

Figure 3

\section{Interaction Effects of Domain and Investment Experience}

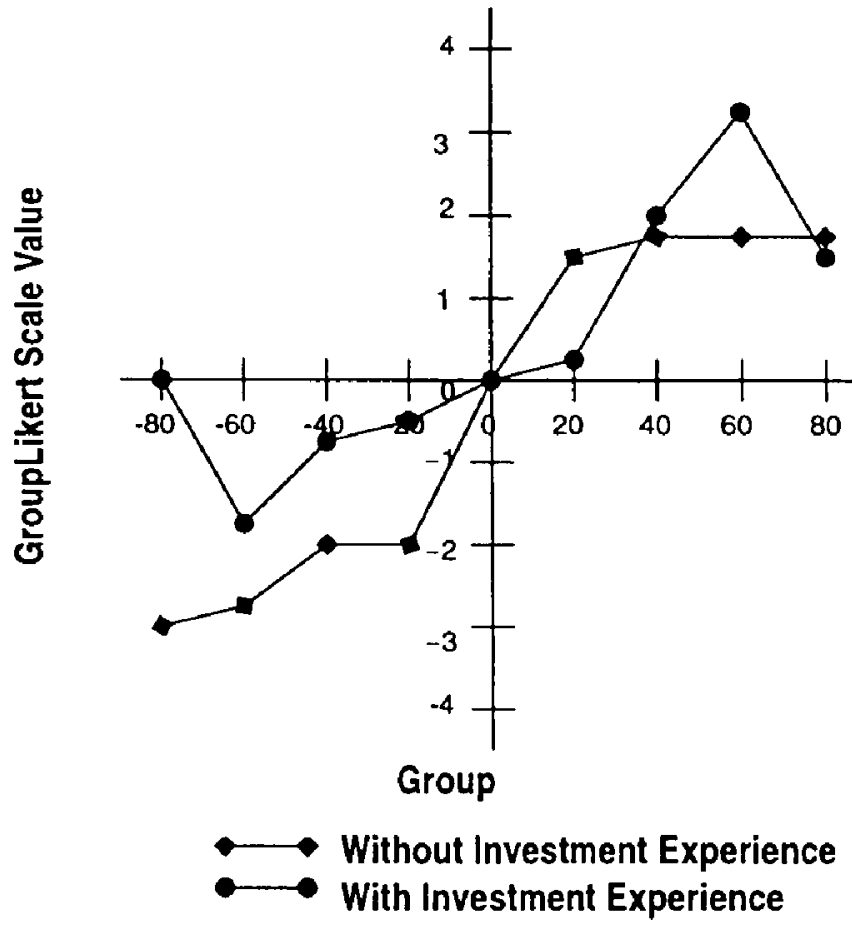


The second hypothesis tests the marginal diminishing sensitivity tenet of the value function. To test this hypothesis, four levels of gain or loss were presented to the subject groups. The null hypothesis would be rejected if the subjects reacted differently based on the level of gain/loss $(20 \%, 40 \%, 60 \%, 80 \%)$.

Comparisons of the means were conducted within each domain. The results support the concept of diminishing marginal sensitivity. In both domains, the evidence did not suggest a difference in reactions to levels of positive or negative financial results $\left(\mathrm{F}_{\mathrm{p} x \mathrm{~s}}=1.24, \mathrm{p}=0.3817 ; \mathrm{F}_{\mathrm{ncg}}=2.21, \mathrm{p}=0.1620\right)$. The domains were further divided by impression management (present/absent) and again by level of investment experience (prior experience/no prior experience). No statistical evidence was found to reject the hypothesis of no difference in reactions among levels of gain or loss, regardless of the number of qualifications made.

The third and fourth hypotheses suggests an ordinal interaction between domain (positive or negative) and impression management (present or absent). Specifically, hypothesis 3 posits that the use of impression management will significantly reduce the effect of negative information, and hypothesis 4 posits that the use of impression management will not significantly improve the effect of positive information.

The average response in each cell is presented in Figure 4. The four levels of change in the positive and negative domains were collapsed to test the overall interaction of domain and impression management. The distance from zero was measured for each of the four cells. The interaction effects were tested using an ANOVA. A statistically significant interaction was found between domain and impression management ( $\mathrm{F}=15.48, \mathrm{p}=.0001)$.

To directly test hypotheses three and four, the data were separated into two sets based on domain and tested for the effect of impression management. In the negative domain, the effect of impression management on the prediction of stock price changes was found to be statistically significant $(F=14.96, p=$ 0.0002 ), supporting hypothesis 3 . That is, the average response was significantly reduced by the presence of commentary explaining the reason for the loss.

In the positive domain, a statistically significant effect was not found $(F=2.52$, $p=.1151)$. This result supports hypothesis 4 in that the presence of impression management did not statistically increase the average response of the subjects.

Because of the effect of investment experience found in the statistical testing of hypothesis 1, the data used to analyze hypotheses 3 and 4 were also divided between investment experience and no investment experience. If subjects with no investment experience are more sensitive to the information provided than subjects with prior investment experience, the results obtained above might be incomplete.

No statistical support was obtained to indicate adding a variable for investment experience to the model affected the results reported above $(F=.73, p=$ 0.3942 ). Within cach experience group, an ordinal interaction occurred with statistically different means in only the negative domain. The means for each group by investment experience are presented in Table 1. The interaction was 
Figure 4

The Effect of Impression Management on Investor Reactions

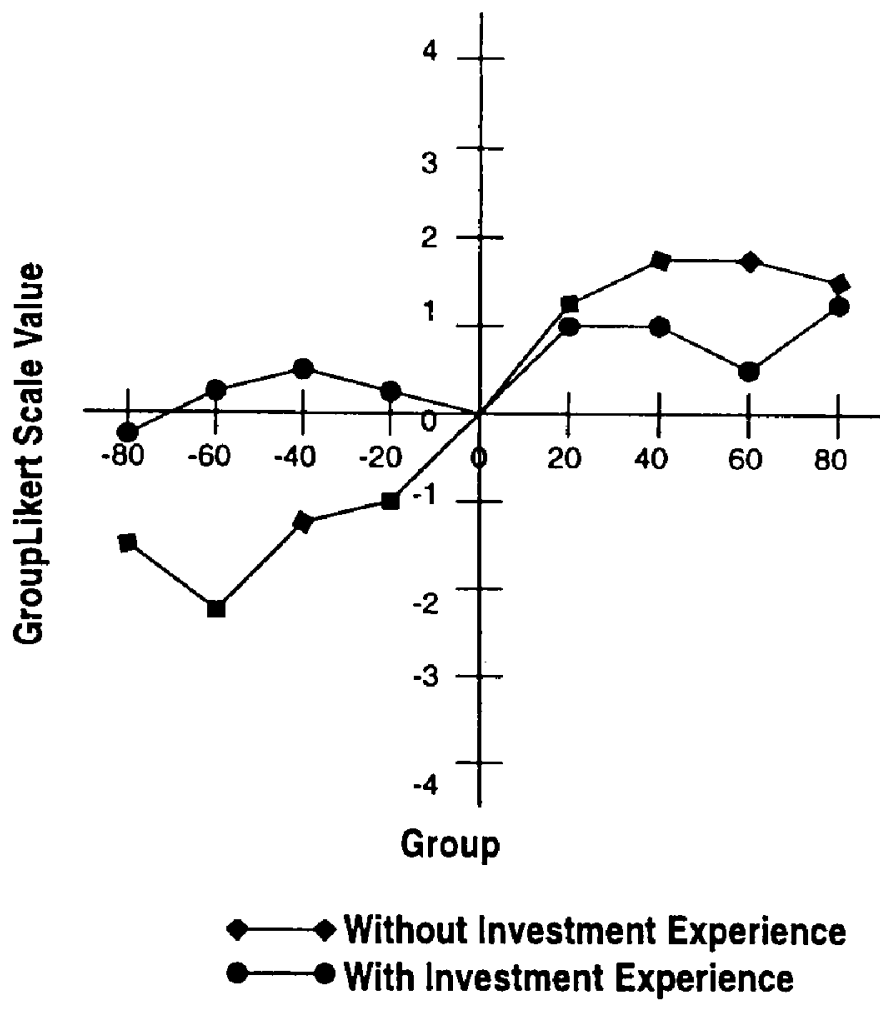

Table 1

Means of Domain and Impression Management By Investment Experience

\begin{tabular}{cccccc}
\hline $\begin{array}{c}\text { Level of } \\
\text { Domain }\end{array}$ & $\begin{array}{c}\text { Impression } \\
\text { Management }\end{array}$ & $\begin{array}{c}\text { Investment } \\
\text { Experience }\end{array}$ & $\mathbf{N}$ & $\mu$ & $\sigma$ \\
\hline & & & & & \\
Positive & Absent & Absent & 42 & 1.69 & 1.72 \\
Positive & Present & Absent & 36 & 1.14 & 2.40 \\
Negative & Absent & Absent & 23 & -2.43 & 1.53 \\
Negative & Present & Absent & 35 & -0.04 & 2.13 \\
& & & & & \\
Positive & Absent & Present & 17 & 1.56 & 2.28 \\
Positive & Present & Present & 23 & 0.87 & 2.26 \\
Negative & Absent & Present & 32 & -0.91 & 2.70 \\
Negative & Present & Present & 25 & 0.32 & 2.34 \\
& & & & & \\
\hline
\end{tabular}


statistically significant (at $\alpha=.10$ ) both when the subjects had prior investment experience $(F=3.59, p=0.0614)$ and when the subjects did not have prior investment cxperience $(F=17.50, p=0.0001)$. Within each investment experience condition, an ordinal interaction occurred with significant differences in the negative domain but not in the positive domain.

\section{Conclusions}

In this study, the value function, as defined by prospect theory, and the role of impression management were tested in a business setting using accounting data. The experiment was based on individual investor reactions to earnings changes with or without supplemental information disclosures. The results are consistent with prior theory within certain limits.

Contrary to the theory of loss aversion, subjects' reactions to financial losses were not different from their reactions to financial gains. When the subjects were divided by investment experience, however, a difference was found in the reactions of the two groups. Subjects were encouraged to utilize only the information provided in the instrument in reaching their predictions for stock price. However, in comparing the results of subjects with investment experience to those without previous experience, bias was indicated. The participants with investment experience tended to respond less predictably than those without investment experience. This suggests that the respondents may have been biased by previous investment experiences or investment knowledge. The subjects with no investment experience were willing to base their predictions of stock price changes on the information presented in the experimental scenario. Subjects with prior investment experience were less willing to accept the loss scenarios as presented in the simple scenarios used for this experiment and displayed a markedly reduced reaction to the information.

The rescarchers were aware of the number of adult, second career and military personnel at this particular university. The researchers did not know, a priori, the large proportion of subjects who would have prior investment experience in these particular classes. The results indicate a difference in reactions between levels of investment experience. Subjects self-selected into these conditions in the current study. A future study could more carefully control for investment experience differences by selecting subjects specifically to fill the investment/ no investment experience cells. More specific investment experience (e.g. financial analysts or advisors) might also be desirable.

For every decision group, the average of all responses to earnings losses and gains was consistent with the concept of diminishing marginal sensitivity. Within the domain of gains and the domain of losses, the reactions were no greater given a range of gains/losses of $20 \%$ to $80 \%$.

A limitation is that the subjects in the current study were asked to assume the role of shareholders in a hypothetical company. No economic incentives were 
presented to motivate their interest in the value of the firm's stock. While the subjects were aware that the stock was in a loss situation, the authors did not have a measure to capture the pain (if any) felt by the loss.

The theory supporting the second hypothesis (diminishing marginal sensitivity) supports a failure to reject the null hypothesis and could be affected by the limitation mentioned above. By biasing the results of hypothesis two toward the null hypothesis, false support could be added to the outcome. The results obtained for hypothesis two, however, are consistent with extant theory and support the null hypothesis in all comparisons: (1) when levels of gain/loss were compared within domain, (2) when levels of impression management (present/ absent) were compared within domain, and (3) when levels of investment experience (present/absent) within impression management group (present/absent) were compared within domain. A future study could use economic incentives to further investigate the lack of reaction to negative earnings information by experienced investors and to validate the results for diminishing marginal sensitivity.

Finally, the reactions in conditions with impression management were less adverse than those without impression management in the domain of losses. When subjects were provided with some form of explanation for the unfavorable earnings results, their predictions were not as pessimistic as when only the negative financial results were presented. Conversely, the results for the decision groups with positive earnings scenarios appeared to be unaffected by impression management.

In summary, this research supports and confirms prior research in the areas of prospect theory and impression management. In addition, these areas are extended by introducing their concepts into a business environment and by using accounting numbers to elicit a reaction to net income changes. To the authors' knowledge, no published research exists in the accounting literature on this topic. Further, this research shows that impression management in the form of additional management commentary can and will affect the interpretation of raw accounting numbers.

\section{References}

Allen, M. W. \& Caillovet, R. H. (1994). Legitimization endeavors: impression management strategies used by an organization in crisis. Communication Monographs, 4456.

American Express Company. (1992). Annual report.

American Express Company. (1993). Annual report.

Ball, R. \& Brown, P. (1968). An empirical evaluation of accounting income numbers. Journal of Accounting Research, 159-178. 
Bazerman, M. (1990). Judgment in managerial decision making. (2nd ed.), New York: John Wiley and Sons.

Brockner, J. (1992). The escalation of commitment to a failing course of action: Toward theoretical progress. Academy of Management Review, 39-61.

Bromley, D. B. (1993). Reputation, image and impression management. West Sussex, England: John Wiley and Sons.

Burns, G. (1995). What's a small investor like you... Business Week, April 17, 83-84.

Chugh, L. C. \& Meador, J. W. (1984). Break the barrier between you and your analysts. Financial Executive, September, 16-21.

De Bondt, W. F. M. \& Thaler, R. (1985). Does the stock market overreact? Journal of Finance, 40, 793-805.

De Bondt, W. F. M. \& Thaler, R. (1987). New evidence on investor overreaction and January excess returns. Journal of Finance, 43, 557-581.

Fuller, R. J. (1996). Amos Tversky. Behavioral finance and Nobel prizes. Financial Analysts Journal, July/August, 7-8.

Giacalone, R. A. (1989). Image control: The strategies of impression management. Personnel, May, 52-55.

Hand, J. R. M. (1990). A test of the extended functional fixation hypothesis. The Accounting Review, October, 740-763.

Hogarth, R. (1989). Judgement and Choice. New York: John Wiley and Sons.

Jones, M. (1996). Accounting narratives: An emerging trend. Management Accounting, April, 41.

Kahneman, D., Knetsch, J. \& Thaler, R. H. (1990). Experimental tests of the endowment effect and the coase theorem. Journal of Political Economy, 1325-1348.

Kahneman, D. \& Tversky, A. (1979). Prospect theory: An analysis of decisions under risk. Econometrica, 263-291.

Kahneman, D. \& Tversky, A. (1984). Choices, values, and frames. American Psychologist, 341-350.

Kaplan, S. E., Pourciau, S. \& Reckers, P. M. J. (1990). An examination of the effect of the president's letter and stock advisory service information on financial decisions. Behavioral Research in Accounting, 63-92. 
King, R., Pownall, G. \& Waymire, G. (1990). Expectations adjustments via timely management forecasts: review, synthesis, and suggestions for future research. Journal of Accounting Literature, 113-144.

Kormendi, R. \& Lipe, R. (1987). Earnings innovations, earnings persistence, and stock returns. Journal of Business, 323-345.

Lev, B. \& Ohlson, J. A. (1982). Market-based empirical research in accounting: A review, interpretation, and extension. Journal of Accounting Research Supplement, 249-322.

Luce, R. D. \& Raiffa, H. (1957). Games and decisions, New York: John Wiley and Sons.

Mayer, P. C. (1995). Electricity conservation: Consumer rationality versus prospect theory. Contemporary Economic Policy, April, 109-116.

Murray, L. H., Rao, A. \& Schmidt, S. M. (1995). Upward impression management. Human Relations, February, 147-166.

Staw, B. M., McKechnie, P. I. \& Puffer, S. M. (1983). The justification of organizational performance. Administrative Science Quarterly, 582-600.

Tversky, A. \& Kahneman, D. (1991). Loss aversion and riskless choice: A reference dependent model. Quarterly Journal of Economics, 1039-1061.

von Neumann, J. \& Morgenstern, O. (1947). Theory of games and economic behavior. (2nd ed.), Princeton, NJ: Princeton University Press.

Wood, R. E. \& Mitchell, T. R. (1981). Manager behavior in a social context: The impact of impression management on attributions and disciplinary actions. Organizational Behavior and Human Performance, December, 356-378.

D. Elaine Sanders is an Associate Professor of Accounting at the University of Texas at San Antonio where she teaches undergraduate and graduate courses in cost and management accounting. She received her Ph.D. in accounting from the University of Oklahoma after working in industry. Dr. Sanders has previously published in a number of journals including Journal of Business Strategies, Journal of Managerial Issues, and Organizational Behavior and Human Decision Processes.

Jane L. Coelho received her Master of Business Administration from the University of Texas at San Antonio. Mrs. Coelho has worked in both public and corporate accounting. She is a Certified Public Accountant and currently has a private practice in San Antonio, Texas. 